\title{
Study on Effectiveness of Staff Welfare Program Regarding Occupational Stress During COVID 19 Pandemic among Nursing Officers
}

\author{
Franny Joel Emmanuel ${ }^{1}$, Yugmi Vala ${ }^{2}$, Tapan $\operatorname{Dodia}^{3}$ \\ ${ }^{1}$ Nursing Tutor; M.Sc. Nursing, Child Health Nursing, Manikaka Topawala Institute of Nursing-CHARUSAT; \\ Changa; Ta. Petlad, Dist.-Anand; Gujarat-38842, India, ${ }^{2}$ Post-Graduate Diploma in nursing Administration, \\ Symbiosis School for Open and Distance Learning, Pune, India, ${ }^{3}$ MBBS, FCCCM, ISCCM, Intensivist, Ruby Hall
}

Clinic, Pune

\begin{abstract}
Background: No wonder who you are and what you are, make your soul strong enough to fight against Stress, move ahead with joy, and let us make stress to be alone. Nursing Care for an individual no matter whether an individual is health or unhealthy, no matter from which age group S/He belongs to, however stress perception is highly subjective ${ }^{1}$. Work related stress amongst nursing fraternity can be generated by copious reasons. These reasons are dangerous for nurses especially during the current scenario of "COVID 19 Pandemic",this stress has been concern throughout the globe. ${ }^{2}$
\end{abstract}

Objectives: Researchers have set the objectives of computing the effectiveness of staff welfare program regarding Occupational stress during "COVID 19 Pandemic" among nurses.

Methodology: Researchers have used quasi experimental research design. 60 Nursing staff from a ICU of a reputed hospital of Pune city were recruited with Consecutive non probability technique. Expanded nursing stress scale (ENSS) has used to measure nurses occupational stress during "COVID 19 Pandemic". This tool is in the form of 5 point likert scale.

Results: Researchers have identified that pre-test and post-test's mean difference is 61.1in experimental group, where as in control group mean difference is 2.3 .

Conclusion: It reciprocates that experimental group pre test post test mean difference has vast difference than control group, thus staff welfare program is effective in order to reduce the occupational stress during "COVID 19 Pandemic" among nursing fraternity .

Keywords: Effectiveness; Staff welfare program; occupational stress; "COVID 19 Pandemic”; nurses.

\section{Introduction}

Nursing is defined as a most kind profession full of knowledge, compassion, and skill. Nurses are the

\section{Corresponding Author:}

\section{Ms. Franny Joel Emmanuel}

Nursing Tutor, M.Sc. Nursing: Child Health

Nursing, "Manikaka Topawala Institute of Nursing-

CHARUSAT, Changa; Ta. Petlad, Dist. - Anand,

Gujarat-38842, India

Ph. No.: 9409026609

e-mail: frannyemmauel.nur@charusat.ac.in heart of the hospital, where they have to deal with copious obstacles in terms of physical, mental, spiritual challenges $^{3}$. Majority of all profession or job has work stress may be physically, socially or even emotionally. Stress can be considered as a long lasting, dangerous and emotional impairment which can affect an individual's health. According to current scenario when globe is suffering with "Corona virus", and nurses are at high risk to get exposed while performing his/her duties, it is very hard to manage between personal and professional life during this pandemic, where majority of the people are having questions on their survivalist. It is a very much important to examine the nursing literature on stress and 
one should make some strategies to reduce occupational stress ${ }^{4}$.

Thus, researcher wants to detect occupational stress among ICU nurses, construct and administer Staff welfare program to reduce level of stress among nurses and so they become strong enough to keep aside stress and give quality of work towards their institute and feel free to work efficiently. ${ }^{5}$ This staff welfare program includes 2 components': "strike balance with maintenance of workplace stress" and "Breathing exercise". During the hospital experience, the researchers had come across manynurses suffering from occupational stress and nurses are not focused from resolving or decreasing this stress. Hence researchers wants to put efforts to decrease this occupational stress. So, that the need for this study is an important aspect to be carried out at the time of this pandemic.

\section{Objectives:}

1. Assess the level of occupational stress during "COVID 19 Pandemic" among nursing officers in experimental group and control group.

2. Compute effectiveness of staff Welfare program regarding occupational stress during "COVID 19 Pandemic".

$\mathbf{H}_{1}$ : There will be a significant difference in post test occupational stress level between experimental group and control group.

\section{Assumptions:}

- Nurses of Selected hospital may have high level of stress level need to reduce their occupational stress level.

- They may develop interest during Staff Welfare Program

- Introducing of staff welfare program may reduce stress in nurses.

\section{Methodology}

Research Design: Quasi Experimental research
design

Setting: One reputed Hospital of Pune City

Subject: Nursing Undergraduates

Sampling techniques: Consecutive non probability technique
Sample size: 60 sample (30 control group, 30 experimental group)

Variables: Demographic variable: Age, Gender, Years of experience, Marital status, Monthly salary, Education qualification, Number of dependency members in family, Year of experience at current hospital, perception of nurses for doctor, perception of nurses for other colleague, skip meal at duty, night Duty is...., are you getting rest/leave enough, Family Type.

Independent variable: Staff welfare Program

Dependent Variable: Occupational Stress

\section{Inclusion Criteria:}

1. Staff who are willing to Participate in the study

2. Staff who can read writes and understand English language.

3. Staff that are registered with nursing council.

4. Staff who is working in medical and surgical ICU

5. Staff who is having at least 1 year of experience of ICU.

6. Staff who works in ICU at the time of COVID 19 Pandemic but not associated with corona positive patients.

\section{Exclusion Criteria:}

1. Staff who are undergone to any alternative therapy.

2. Staff who has experience sudden loss

3. Staff who is having any other psychological or physical problems

4. Staff who is not available at the time of post tests

5. Staff who can't attend all the sessions of staff welfare program

\section{Explanation of the tool: Tool comprise of 2 sections:}

Section 1: Deals with 14 demographic variables. It is in the form of Semi structured Questioners with multiple choice answers

Section 2: Self modified "Expanded nursing stress scale (ENSS)" has used to measure nurses occupational stress. The ENSS is an expanded and updated revision of classic nursing scale developed by Gray-Toft and Anderson (1981). ${ }^{6}$ This scale is used to assess 
occupational stress in nurses. It is an expanded version of the original 34-items Nursing stress scale. ENSS contained 57 items in nine subscales. The 57 each items were arranged in 5 point Likert response scale.

Total score 285 which classified into, absolute grading is used

- 57: No Stress

- 58-133: Mild Stress

- 134-209: Moderate Stress

- 210-285: Sever stress

The researcher modified the expanded nursing stress scale to assess the level of stress among nurses.

Description of staff welfare program: In this research study researchers have created one program for reduction of occupational stress, it includes two components: "Strike balance with maintenance of workplace stress" and "Breathing exercise". Researchers have undergone with online certificate course on maintenance of workplace stress from udemy online course.

Manage Workplace Stress and Strike a Balance: In this component nurses will able to Identify \& understand stressors, how to manage them with these techniques, How to determine priorities \& values, Set smart \& measurable goals, how to balance an individual's Personal life and work place life by setting up plethora of priorities and factoring in some downtime, various team building, motivating activities are been included in this welfare program. ${ }^{7}$

Breathing exercise: Sample are trained for 3 breathing exercise such as "alternative breathing", "Stimulating breathing technique", "Abdominal breathing." Each breathing exercise will long for $10 \mathrm{~min}^{8}$

Statistics: Descriptive statistics: Mean, SD, frequency distribution

Inferential Statistics: Unpaired $t$ test

\section{Result}

The collected statistics were edited, tabulated, analyzed, interpreted furthermore findings were presented in the shape of tables and graphs representing in the following segments.
Segment I: Plotting data Frequency and Percentage data distribution of Population characteristics Variable

Segment II: Data Frequency and percentage distribution of occupational stress score

Segment III: Unpaired $t$ test calculation

\section{Segment I: Plotting Data Frequency and Percentage Data Distribution of Population Characteristics Variable}

As per demographic data collection table shows that in experimental group 24 no. of nurses $(80 \%)$ are in between $20-30$ years of age, 5 no. of nurses $(16.67 \%)$ are in between $32-40$ years of age, 1 no. nurses $(3.33 \%)$ is in between $42-60$ years of age. In control group 25 no. of nurses $(83.34 \%)$ are in between $20-30$ years of age, 4 no. of nurses $(13.33 \%)$ are in between $31-40$ years and 1 no. of nurses $(3.33 \%)$ is in between $41-60$ years

As per gender in control group 22 no. of nurses $(70 \%)$ are female, 8 no. of nurses $(30 \%)$ are male. In experimental group 24 no. of nurses $(80 \%)$ are female, $6(20 \%)$ nurses are male.

In experience variable majority $13(43.34 \%)$ nurses have experience of 3-5 years, 10(33.33\%) nurses have experience of 1-2 years and 7(23.33) nurses have experience of more than 5 years in control group. While in experimental group majority 13(43.34\%) nurses have experience of 1-2 years, 11 nurses have experience of 3-5 years and $6(20 \%)$ of nurses have experiences of more than 5 years.

As permarital data 20 no. (66.67\%) of nurses are unmarried, 10 no. (33.34\%) of nurses are married and in control group. Where in experimental group 17 (56.66\%) are unmarried, 13 (43.34\%) are married.

$21(70 \%)$ nurses are satisfied from their salary and $9(30 \%)$ nurses are not satisfied from their salary in control group while in experimental group 22(73.34\%) nurses are satisfied from their salary and $8(26.66 \%)$ nurses are dissatisfied from their salary.

Education qualification in control group 25(83.33\%) nurses certified from GNM course, 5(16.67\%) certified from BSC course. Education qualification in experimental group include 25(83.33\%) nurses certified from GNM course, 4 nurses certified from BSC nursing course, $1(3.33 \%)$ certified from post basic BSC nursing course as per table number 4 . 
According to table no. 4, in control group 10(33.34\%) nurses has more than 2 dependency members in family, $9(30 \%)$ nurses has none dependency member in family, $7(23.33 \%)$ nurses has 2 dependency members in family, $4(13.33 \%)$ nurses has 1 dependency member in family. Number of Dependency member in family in experimental group include $13(43.34 \%$ ) nurses has none member, $12(40.00 \%)$ nurses has 2 members, $3(10.00 \%)$ nurses has more than 2 members, $2(6.66 \%)$ nurses has 1 member.

As per Year of experience in current hospital in control group $17(56.67 \%)$ nurses have 1 to 2 year experience, $11(36.66 \%)$ nurses have 3 to 5 year experience, $2(6.66 \%)$ nurses have more than 5 years experience. Year of experience in current hospital in experimental group include 20(66.67\%) nurses have 1 to 2 year experience, $9(30.00 \%)$ nurses have 3 to 5 year experience and $1(3.33 \%)$ nurses have more than 5 years of experience.

Perception of nurse for doctor in control group $16(53.33 \%)$ nurses has excellent perception for doctors, $10(33.33 \%)$ nurses has Average perception for doctor, $4(13.34 \%)$ nurses has Poor perception for doctor. Perception of nurse for doctor in experimental group include 20(66.67\%) nurses has excellent perception for doctor, $7(23.33 \%)$ nurses has Average perception for doctor, and $3(10.00 \%)$ nurses has Poor perception for doctor as per data.

As per data, perception of nurse for other collages in control group 22(73.34\%) nurses have Excellent perception for other collages, $8(26.66 \%)$ nurses have Average perception for other collages, $0(0 \%)$ nurses have Poor perception for other collages. Perceptions of nurse for other collages in experimental group include
$24(80.00 \%)$ nurses have excellent perception for other collages, 5(16.67\%) nurses have Average perception, and $1(3.33 \%)$ nurses have Poor perception for other collages.

Skip meal at duty in control group $17(56.67 \%)$ nurses never skip meal at duty, 13(43.33\%) nurses sometime skip meal at duty. In experimental group include $23(76.67 \%)$ nurses never skip meal at duty, $7(23.33 \%)$ nurses skip sometime meal at duty.

Night duty in control group 26(86.66\%) nurses feel safe night duty, 4(13.34\%) nurses feel reasonable safe night duty. Night duty in experimental group include 28(93.34\%) nurses feel safe night duty, 2(6.66\%) nurses feel reasonable safe night duty as per above data.

As per above table nurses who are getting rest enough in control group 19(63.33\%) nurses getting rest some time, $6(20.00 \%)$ nurses never getting rest and $5(16.67 \%)$ nurses always getting rest. Nurses who are getting rest enough in experimental group include $18(60.00 \%)$ nurses are getting sometime rest, $8(26.66 \%)$ nurses always getting rest, 4(13.34\%) nurses never getting rest.

Family type in control group 16(20.00\%) nurses are belongs form extended family type 13(43.33\%) nurses are belongs form joint family, 11(36.67\%) nurses are belongs from Nuclear family type. Family type in experimental group include $16(53.34 \%$ ) nurses are form joint family type, $9(30 \%)$ nurses are form Nuclear family type, $5(16.66 \%)$ nurses are for extended family type as per above table.

Segment II: "Data Frequency and Percentage Data Distribution of Emotional Intelligence Score"

Table 1: Data Frequency and Percentage data distribution of occupational stress score

\begin{tabular}{|c|c|c|c|c|c|c|c|c|}
\hline \multirow{3}{*}{ Class Interval } & \multicolumn{4}{|c|}{ Experimental Group } & \multicolumn{4}{|c|}{ Control Group } \\
\hline & \multicolumn{2}{|c|}{ Pre Test } & \multicolumn{2}{|c|}{ Post Test } & \multicolumn{2}{|c|}{ Pre Test } & \multicolumn{2}{|c|}{ Post Test } \\
\hline & Frequency & $\%$ & Frequency & $\%$ & Frequency & $\%$ & Frequency & $\%$ \\
\hline 57: No stress & 0 & $0 \%$ & 1 & $3.33 \%$ & 0 & $0 \%$ & 0 & $0 \%$ \\
\hline 58-133: Mild stress & 5 & $16.67 \%$ & 22 & $73.34 \%$ & 9 & $30 \%$ & 6 & $20 \%$ \\
\hline 134-209: Moderate stress & 10 & $33.33 \%$ & 7 & $23.33 \%$ & 9 & $30 \%$ & 9 & $30 \%$ \\
\hline 210-285: Severe stress & 15 & $50 \%$ & 0 & $0 \%$ & 12 & $40 \%$ & 15 & $50 \%$ \\
\hline
\end{tabular}


Segment III: "Effectiveness of Staff Welfare Program on Occupational Stress of ICU Staff Nurses"

Table 2: Mean, standard deviation, mean difference and unpaired ' $t$ ' test value of pre-test and post-test score in experimental group

\begin{tabular}{|l|l|c|c|c|c|c|c|c|}
\hline \multicolumn{2}{|l|}{ Variable } & Mean & Mean difference & SD & DF & t- value & Table value & Significant \\
\hline \multirow{2}{*}{$\begin{array}{l}\text { Occupational } \\
\text { stress score }\end{array}$} & Pre-test & 194.7 & \multirow{2}{*}{61.1} & 13 & 29 & 8.63 & 2.04 & $\mathrm{~S}^{*}$ \\
\cline { 2 - 8 } & Post-test & 133.6 & & & & & \\
\hline
\end{tabular}

$*(0.05,29) 2.04$

Inference: This table Depicts mean, standard deviation of pre-test and post-test in experimental group with the mean difference is $61.1, \mathrm{SD}$ is 13 , paired' is 8.63 value and $\mathrm{p}$ value, df value of pre-test and post-test stress level score.

Table 3: Mean, standard deviation, mean difference and ' $t$ ' value of pre-test and post-test score in control group

\begin{tabular}{|l|l|c|c|c|c|c|c|c|}
\hline \multicolumn{2}{|l|}{ Variable } & Mean & Mean difference & SD & DF & t- value & Table value & Significant \\
\hline \multirow{2}{*}{$\begin{array}{l}\text { Occupational } \\
\text { stress score }\end{array}$} & Pre-test & 182.93 & 2.3 & 14.82 & 29 & -1.16 & 2.04 & NS* \\
\cline { 2 - 8 } & Post-test & 185.23 & & & & & \\
\hline
\end{tabular}

$*(0.05,29) 2.04$

Inference: This table Depicts mean, standard deviation of pre-test and post-test in experimental group with the mean difference is 2.3 , SD is 14.82 , paired' is -1.16 value and $\mathrm{p}$ value, df value of pre-test and post-test stress level score

\section{Discussion}

Pre-test stress level: Mean pre-test score $=194.7$, pre-test stress level score reveals that 5 nurses $(16.67 \%)$ are having mild occupational stress, 10 nurses (33.33\%) are having moderate occupational stress and 15 nurses $(50 \%)$ are having severe occupational stress. Posttest stress level: Mean post-test score $=133.6$, where post-test score reveals that 1 nurse $(3.33 \%)$ is having no occupational stress, 22 nurses $(73.34 \%)$ are having mild occupational stress, 7 nurses $(23.33 \%)$ are having moderate occupational stress and no one is having severe occupational stress. Where the control group Pretest stress level: Mean pre-test score $=182.93$, pre-test stress level score reveals that 9 nurses (30\%) are having mild occupational stress, 9 nurses $(30 \%)$ are having moderate occupational stress and 12 nurses $(40 \%)$ are having severe occupational stress. Post-test stress level: Mean post-test score $=185.23$, post-test stress level score reveals that 6 nurses $(20 \%)$ are having mild stress, 9 nurses (30\%) are having moderate stress, 15 nurses $(50 \%)$ are having severe stress.

\section{Conclusion}

To the best of our comprehension, this literature review implicates the relationship between Occupational stress and nursing fraternities are higher. With specific association to all above mentioned studies we researchers have come up with the serious note of discussion. ${ }^{6}$ These Review divulge plethora of facts, these facts are fascinating and interesting. This study review that there is a different score of occupational stress among nursing officers after the intervention of staff welfare program, Researchers believe that to boost the favorable condition of nursing staff and to reduce the occupational stress, an individual should emphasize to receive staff welfare program. This may also lead in positive social change, reducing emotional conflicts, resulting in high productivity. ${ }^{9}$

Recommendations: In the light of the above finding and personal experience of the investigator the following recommendations are offered: The study can be replicated on larger sample; thereby finding can be generalized for a larger sample. Nurses working in 
any set up can use the staff welfare program (manage workplace and strike a balance and breathing exercises) to decrease occupational stress level. The department should also create such kind of Protocols to keep their nurses fit and fine.

\section{Suggestions:}

- A study can be replicated on a large sample which will facilitate more reliable research.

- A similar study can be conducted in different setting.

Ethical Consideration: Inform consent was obtained from the samples who have participated in research study in the consent form. Confidentiality of all sample's information is maintained properly.

Conflict of Interest: There is no any means of conflict of interest within the researchers

Funding Agency: Researchers have not received any fund from any agency.

\section{References}

1. B M. Self-reported stress and its effects on nurses.PubMed-NCBI [Internet]. Ncbi.nlm.nih.gov. Available from: https://www.ncbi.nlm.nih.gov/ pubmed/12212429

2. Novel Coronavirus (2019-nCoV) situation reports [Internet]. Who.int. 2020. Available from: https:// www.who.int/emergencies/diseases/novelcoronavirus-2019/situation-reports

3. Nola Pender: Health Promotion Model (Nursing Theory Guide) [Internet]. Nurseslabs. 2020.
Available from: https://nurseslabs.com/nolapender-health-promotion-model/9.

4. B.T.Basvanthappa,"NURSING RESEARCH", 2nd edition, Jaypee Brothers Medical Private Ltd, page no. 61-63

5. Annals of Indian Psychiatry: Table of Contents [Internet]. Anip.co.in. 2020. Available from: http:// www.anip.co.in/searchresult.asp?I1.x $=0$ \& I1.y $=0$ $\&$ search $=\mathrm{A}+$ profile + of + occupational + stress $+\mathrm{in}+\mathrm{n}$ urses

6. Effect of Stress Management Interventions on Job Stress among Nurses working in Critical Care Units - ProQuest [Internet]. Search.proquest.com. 2020. Available from: https://search.proquest.com/openv iew/5fd1cd48c7bbfb57613e665fbd935054/1? pqorigsite $=$ gscholar $\& \mathrm{cbl}=35042$

7. F Polit, Cheryi Tatano Beek, "Nursing Research principles and method", 7th edition, Lippincott Williams and Wilkins Publishers-Philadelphia, Page no. 450-452

8. French SE Lenton R, Walters V, Eyles J. An empirical evaluation of expanded nursing stress scale. J Nurs Meas 2000:8 160-178.

9. Karl Pearson's Formula for Finding the Degree of Correlation [Internet]. Economics Discussion. 2020. Available from: http://www.economicsdiscussion. net/correlation/karl-pearsons-formula-for-findingthe-degree-of-correlation/2579 